\title{
METABOLIC ADAPTATION STRATEGY USING Zymomonas mobilis CP4 CELLS FOR THE PRODUCTION OF SECOND GENERATION ETHANOL
}

\author{
Danielle da Silveira dos Santos Martins, Elcio Ribeiro Borges, Viviane Castelo Branco Reis, \\ Fernando Araripe Gonçalves Torres, Nei Pereira Jr. \\ Laboratories of Bioprocess Development, School of Chemistry, Federal University of Rio de Janeiro, 21949- \\ 900, Laboratories of Bioprocess Development, School of Chemistry, Federal University of Rio de Janeiro, \\ 21949-900, \\ Laboratories of Bioprocess Development, School of Chemistry,Federal University of Rio de Janeiro, 21949- \\ 900 , \\ Cellular Biology Department, University of Brasília, 70910-900, Cellular Biology Department, University of \\ Brasília, 70910-900,
}

\begin{abstract}
During the past few decades, considerable effort has been made to utilize agricultural and forest residues as biomass feedstock for the production of bioethanol as an alternative fuel. The bacterium Zymomonas mobilis was shown to be extremely attractive for the production of second-generation ethanol from glucose of the cellulose fraction due to its ability to uptake high amounts of this sugar, resulting in high ethanol productivity values. However, the wild-type strains are unable to metabolize xylose that arises from the hemicellulose fraction. Molecular biology techniques were incorporated to render the strain used in this study capable of fermenting xylose into ethanol and thus increase the efficiency of secondgeneration ethanol production. Thus, the aim of this study was to evaluate the performance of a recombinant strain of $Z$. mobilis in simultaneous saccharification and co-fermentation (SSCF) processes, in which the fermentation of both sugars (glucose and xylose) occurs in one step. Regarding the genetic transformation,the 1,565 kb Z. mobilis plasmid pZMO1 was chemically synthesized and cloned into a synthetic vector that contains the $E$. coli and $Z$. mobilis replication checkmark origin,the $\mathrm{XI}, \mathrm{XK}, \mathrm{TAL}$, and TKL genes and tetracycline resistance. Metabolic adaptation was performed by transferring the recombinant strain to media containing increased xylose concentrations. Then, an experimental response surface methodology was used to evaluatethe addition of glucose and xylose with different concentrations, as well as the incorporation of hemicellulosic hydrolyzate in different proportions. The recombinant $Z$. mobilis CP4 strain reached $25 \mathrm{~g} / \mathrm{L}$ ethanol, confirming that approximately $50 \%$ of this pentose was consumed in the SSCF process when using $30 \%$ solids, $20.5 \%$ hemicellulose hydrolysate, $10 \mathrm{mg} / \mathrm{L}$ tetracycline, an enzyme load of $25 \mathrm{FPU} / \mathrm{g}$ cellulignin, and $10 \%$ of the initial inoculum.
\end{abstract}

\section{Indexing terms/Keywords}

Ethanol 2G; Sugarcane bagasse; Zymomonas mobilis; Metabolic adaptation; SSCF.

\section{Academic Discipline And Sub-Disciplines}

Biotechnology, Biochemical, Microbiology, Bioprocess Engineering, Biochemical Engineering.

\section{SUBJECT CLASSIFICATION}

Biotechnology, Biochemistry, Applied Microbiology, Bioprocess.

\section{TYPE (METHOD/APPROACH)}

Statistics for Experimenters; Pretreatment of Lignocelulosic Materials; Basic Techniques in Molecular Biology; Metabolic Adaptation.

\section{Council for Innovative Research}

Peer Review Research Publishing System

\section{Journal: JOURNAL OF ADVANCES IN BIOTECHNOLOGY}

\author{
Vol .5, No.1 \\ www.cirjbt.org , jbteditor@gmail.com
}




\section{INTRODUCTION}

Sugarcane bagasse, the main solid residue generated in the production of ethanol from sugarcane juice, is considered an excellent lignocellulosic raw material despite being used for energy production in industrial distillery units. However, it is still produced in large amounts, and a large part of it is considered surplus. In this context, it is estimated that sugarcane production will reach approximately 660 million tons in the 2014/2015 harvest season, resulting in approximately 200 million tons of sugarcane bagasse [1].

For the efficient production of ethanol from sugarcane bagasse, i.e.,second-generation ethanol (ethanol 2G), the following steps are required to fraction the main lignocellulosic components: physical/physical-chemical pretreatments and enzymatic hydrolysis simultaneously or separately from fermentation. These steps are necessary to provide carbohydrates (hexoses and pentoses) that must be converted to ethanol by fermenting microorganisms. First, acid pre-treatment has been shown to be an interesting alternative [2] because in addition to disrupting the lignocellulosic complex, it causes hemicellulose hydrolysis, resulting in a xylose-rich hydrolysate. The liquid containing the hemicellulosic hydrolysate is separated from the solid fraction, which mainly consists of cellulose and lignin, i.e., cellulignin. A partial delignification stage of this solid fraction has been shown to be essential to increase the accessibility of the enzymes to the cellulose fibers [3], resulting in hydrolysates containing high glucose concentrations.

Zymomonas mobilis, which exists in natural sources, such as fruits, and as a "beneficial" contaminant in the alcohol fermentation industry, is capable of producing ethanol efficiently from glucose and fructose sugars via the EntnerDoudoroff pathway. This microorganism uses small fractions of sugar as a carbon source, and approximately $98 \%$ of the sugar is used for fermentation. Thus, Z. mobilis is widely used in the manufacture of beverages, milk enriched with fermentable sugars and traditional drinks,such as Pulque [4]. Due to its high potential as a fermentation agent, $Z$. mobilis has been the subject of numerous studies, many of which show promising results in terms of ethanol production when compared with the traditional Saccharomyces cerevisiae, which is largely used in industrial distilleries [5].

To enable the commercial production of lignocellulosic ethanol, an efficient conversion of the main carbohydrates arising from hemicellulose and cellulose hydrolysates into ethanol $2 \mathrm{G}$ is necessary. Although glucose fermentation is carried out efficiently by $Z$. mobilis, as well as by Saccharomyces cerevisiae, the same level of efficiency is not achieved with the conversion of xylose, the main component of the sugarcane bagasse hemicellulose fraction. According to Lynd \& Zhang (2010), the use of microorganisms that are able to ferment glucose and xylose can increase ethanol production by approximately $20 \%$ with the adoption of the technological concept of simultaneous saccharification and co-fermentation (SSCF) compared to the production of only glucose from the cellulose fraction [6].

Because the ability to utilize only glucose, fructose or sucrose as an energy source limits the potential of $Z$. mobilis for the industrial production of ethanol [7], genetic engineering and metabolic adaptation were applied to enable this bacterium to ferment xylose, offering an excellent opportunity for process improvement.

\section{Application of genetic engineering in Z. mobilis cells}

General genetic tools have been developed for $Z$. mobilis since the 1980 s, including native plasmids, broad host-range vectors or shuttle vectors, expression systems, and transfer, promoter, and reporter genes, as reviewed elsewhere [8]. The pioneering work of Liu et al. [9] and Feldman et al. [10], which introduced xylose isomerase (XI) and xylulokinase (XK) genes from Xanthomonas campestris and Klebsiella pneumoniae in Z. mobilis, obtained limited success. These enzymes are responsible for xylose assimilation; however, the enzymes transaldolase (TAL) and transketolase (TKT) promote the metabolism thereof, being essential for the production of ethanol $[8,11]$.

The same genes encoding these enzymes from $E$. coli were also introduced into the bacterium Zymobacter palmae. After metabolic adaptation in xylose-containing medium, the microorganism reached $95 \%$ efficiency from the fermentation of glucose and xylose [12], higher than the efficiency reported in the study by Mohagheghi et al. [13], who achieved 76\% efficiency with the use of $75 \%(\mathrm{v} / \mathrm{v})$ of the pentose-derived hemicellulosic hydrolysate by $Z$. mobilis. Thus, Zhang et al. [14] demonstrated that the co-expression of XI, XK, TAL and TKT, derived from Escherichia coli, allowed Z. mobiles to coferment xylose and glucose, reaching $11 \mathrm{~g} / \mathrm{L}$ ethanol and resulting in a yield of $0.44 \mathrm{~g}$ ethanol $/ \mathrm{g}$ xylose consumed. This yield corresponds to a fermentation efficiency of $86 \%$. However, with glucose and glucose/pentose media, the recombinant strain CP4 (pZB5) reached $94 \%$ and $95 \%$ efficiency after 16 and $30 \mathrm{~h}$ of cultivation, respectively.

Several articles reported the fermentation of xylose present in the hemicellulose fraction of agro-industrial waste. Mohagheghi et al. [15] used waste acid hydrolyzed corn processing, in which fermentation resulted in an ethanol concentration of $53 \mathrm{~g} / \mathrm{L}$. Zhang \& Lynd [16] found that the Z. mobilis 8b microorganism (derived from 31821-pZB5) performed better than $S$. cerevisiae RWB222 when considering the waste paper industry hydrolyzate in the SSCF process. Both microorganisms performed quite similarly, producing ethanol concentrations of 29 and $23 \mathrm{~g} / \mathrm{L}$ and obtaining yields of 0.47 and $0.40 \mathrm{~g} / \mathrm{product} / \mathrm{g}$ sugar consumed, respectively. Davis et al. [17] have also used hemicellulosic hydrolyzate from wheat kernels, reaching an ethanol concentration of $11 \mathrm{~g} / \mathrm{L}$ and a residual xylose of $12 \mathrm{~g} / \mathrm{L}$ using the ZM4 (pZB5) strain without supplementation. In subsequent studies, $5 \mathrm{~g} / \mathrm{L}$ yeast extract and $40 \mathrm{~g} / \mathrm{L}$ glucose was added to the medium, obtaining $28 \mathrm{~g} / \mathrm{L}$ ethanol and $2.6 \mathrm{~g} / \mathrm{L}$ residual xylose after $18 \mathrm{~h}$.

Recently, some authors have reported different strategies: Zhang et al. [18] cited the creation of heat-tolerance strains that use low nutritional requirements, which would be beneficial for the ethanol industry; in addition, recombinant $Z$. mobilis mutants can produce ethanol efficiently at high temperatures using low nutritional requirements, yielding an ethanol concentration of $25 \mathrm{~g} / \mathrm{L}$ from $60 \mathrm{~g} / \mathrm{L}$ glucose added to an RM medium. Caimi et al. [19] reported that ribulose 
accumulation reduces ethanol production in recombinant $Z$. mobilis colonies grown on xylose. Thus, the authors genetically engineered a microorganism that produces the ribose-5-phosphate isomerase at high concentrations, reducing ribulose accumulation, and the production of ethanol increased from $5 \%$ to $15 \%$ (w/ v) using $100 \mathrm{~g} / \mathrm{L}$ xylose.

The incorporation of molecular biology techniques is necessary to make progress in second-generation ethanol production and to provide the strains used in this study that are also able to ferment xylose into ethanol. In this context, the aim of this work is SSCF process development (simultaneous saccharification and co-fermentation), in which the fermentation of both sugars occurs in one step.

In this context, the theoretical yield of the ethanol production from xylose is $0.51 \mathrm{~g}$ ethanol $/ \mathrm{g}$ xylose $(1.67 \mathrm{~mol} / \mathrm{mol})$, generating 1 ATP $\mathrm{mol} / \mathrm{mol}$ pentose. Aristidou \& Penttilä [20] found that the new metabolic pathway promotes the conversion of 5 moles of ethanol from 3 moles of xylose according to the following stoichiometric equation:

$$
3 \text { xylose }+3 \mathrm{ADP}+3 \mathrm{Pi} \rightarrow 5 \text { ethanol }+5 \mathrm{CO}_{2}+3 \mathrm{ATP}+3 \mathrm{H}_{2} \mathrm{O} \text {. }
$$

\section{MATERIALS AND METHODS}

Feedstock: Sugarcane bagasse (Saccharum spp.) was kindly provided by the Costa Pinto Distillery (SP, Brazil). This lignocellulosic residue was submitted to an acid pretreatment, followed by solid separation and alkali delignification, resulting in a material used for enzymatic hydrolysis and fermentation, detailed as follows.

Pretreatment of Cellulignin: The following conditions were used for sugarcane bagasse acid pretreatment: $\mathrm{H}_{2} \mathrm{SO}_{4} 1 \%$ $(\mathrm{v} / \mathrm{v})$, solid/liquid ratio $1: 2$, temperature $121^{\circ} \mathrm{C}$, and duration of $30 \mathrm{~min}$ [2]. After pretreatment, the aqueous phase was removed by pressing filtration, and the remaining solid (acid cellulignin) was subjected to an alkaline delignification with $\mathrm{NaOH}$ at a concentration of $4 \%(\mathrm{w} / \mathrm{v})$ and with a solid/liquid ratio of $1: 20$. Then, the acid cellulignin was exposed to a temperature of $121^{\circ} \mathrm{C}$ for $30 \mathrm{~min}$ [21]. Thereafter, the alkaline-pretreated cellulignin was washed with distilled water several times until the aqueous phase remained clear. This solid matter with increased cellulose accessibility was subjected to enzymatic hydrolysis by a commercial preparation (Multifect, Genencor, USA). The enzymatic activities were determined by filter paper activity, as recommended by Ghose, [22] and are expressed as filter paper units (FPU) per milliliter of mixture.

Microorganism and Inoculum: The native Z. mobilis CP4 used in this work was kindly provided by the Department of Antibiotics of the Federal University of Pernambuco (Brazil). The strain was grown in a liquid medium (20 g L $\mathrm{g}^{-1} \mathrm{glucose}^{-1}$ and $5 \mathrm{~g} \mathrm{~L}^{-1}$ of yeast extract), as recommended by Swing and De Ley, at $30^{\circ} \mathrm{C}$ for $24 \mathrm{~h}$ and maintained at $4^{\circ} \mathrm{C}$.

SSCF Experiments: Batch fermentation experiments were performed in 500mL Erlenmeyer flasks with a working volume of $100 \mathrm{~mL}$ to define the optimum process conditions (solid/liquid ratio, enzyme load and cell concentration). Additionally, fermentations were carriedout in a 1.5L bioreactor (BIOFLO III, New Brunswick Scientific, USA) with temperature, $\mathrm{pH}$, and agitation controlled. The reactor was operated with a working volume of $500 \mathrm{~mL}$, and the temperature and $\mathrm{pH}$ were set at $30^{\circ} \mathrm{C}$ and 5.0 , respectively. The $\mathrm{pH}$ was monitored using a sterilizable $\mathrm{pH}$ electrode and controlled by adding $1 \mathrm{M} \mathrm{KOH}$. The kinetics of SSCF performed in a bioreactor were evaluated under the optimum conditions established in the shake flask experiments. The experiments were performed under the principles of the statistical methodology of response surfaces, that is, a statistical model widely used to study the aggregate effect of several variables and to seek optimum conditions for a multivariable system [23]. The data were statistically analyzed using "Design Expert" software (7.1.6., Stat-Ease).

Analytical Methods: Samples were analyzed for glucose, cellobiose, and ethanol concentrations by high-performance liquid chromatography (HPLC) using a chromatographic system (WATERS) consisting of an HPX-87p (Bio-Rad) column, WATERS 510 pump, refractive index detector WATERS 410, and HP 3390A integrator. The standard solution consists of cellobiose, glucose, and ethanol concentrations of 5,10 , and $15 \mathrm{~g} / \mathrm{L}$, respectively. The end of fermentation was determined by the stabilization of ethanol production, as verified by the reading of two consecutive and equal values of alcohol content.

\section{Applications of Genetic Engineering}

Gene designer: The synthetic genes encoding xylose isomerase, xylulokinase, transaldolase and transketolase as well as two operons, each under the control of a strong constitutive promoter pGAP of $Z$. mobilis, were constructed by chemical synthesis at Advanced Life Sciences Company Technologies, Inc., from genome data for $E$. coli and $Z$. mobilis. The Z. mobilis Plasmid pZMO1 (1,565 kb) [24], which demonstrated stability in the bacteria, was also chemically synthesized and cloned into a synthetic bifunctional vector for $Z$. mobilis and $E$. coli (Figure 1). This vector presents the $E$. coli origin of replication and tetracycline resistance. In this context, the well-defined segments of $E$. coli facilitate the maintenance of plasmid because the gene of $Z$. mobilis includes sequences responsible for replication.

A control that has a plasmid containing only the genes for thetetracycline resistance and the replication origin from $Z$. mobilis and E. coli was also developed, named ORl; the plasmid containing all genes described, in addition to the genes of xylose metabolism (XI, XK, TAL and TKT), was named ORI Zymo. Figure 1 shows the organization of the dual-system operon ( $3.2 \mathrm{~kb}$ on average) for the assimilation and metabolism genes of xylose, under the control of the pGAP promoter, inserted into the plasmid pZMO1. 
Gene amplification: One microliter(50 ng) of pZM01 was used for the amplification of genes by genetic transformation into E. coli $\mathrm{DH} 5 \alpha$. The plasmid was added to each aliquot of competent cells and incubated on ice for $45 \mathrm{~min}$. Subsequently, heat shock was performed at $42^{\circ} \mathrm{C}$ for $90 \mathrm{~s}$, followed by incubation at $37^{\circ} \mathrm{C}$ for 45 min and stirring at 200 rpm using $1 \mathrm{~mL}$ of LB medium Then, the cells were plated on LB medium in the presence of the antibiotic (tetracycline, 10 $\mathrm{mg} / \mathrm{L})$ at $37^{\circ} \mathrm{C}$ for $24 \mathrm{~h}$. This method, adapted from Sambrook \& Russell (2001), has often been used without sophisticated equipment [25].

DNA extraction: Initially, the transformed E. coli cultures were grown in $200 \mathrm{~mL}$ of LB medium containing $10 \mathrm{mg} / \mathrm{L}$ tetracycline at $37^{\circ} \mathrm{C}$ for $24 \mathrm{~h}$. Large-scale DNA extraction, developed according to the methodology of Azevedo et al.[25], was performed after the $E$. coli transformation procedure (discussed above).

Competent cells of $\boldsymbol{Z}$. mobilis: Regarding the insertion of genes by processing,the cells must be made competent to enable the introduction of exogenous DNA in the selected host. Therefore, the competent cell protocol of $Z$. mobilis developed in this work was based on Liang Lee's methodology [26]. After reaching 0.36 of Abs 600 , the inoculum (100 mL) was centrifuged at $4,000 \mathrm{rpm}$ for $5 \mathrm{~min}$ at $4^{\circ} \mathrm{C}$, the supernatant was discarded and the pellet was resuspended in $10 \mathrm{~mL}$ of sterile distilled water solution (added with $10 \%$ glycerol supplemented with $0.85 \% \mathrm{NaCl}$ ). The centrifugation step was repeated under the same conditions, followed by the addition of $2 \mathrm{~mL}$ of solution containing distilled water (10\% glycerol).

Exogenous Plasmid: The plasmid was extracted after lyophilization concentration, and the volume was then adjusted to $30 \mu \mathrm{L}$. After measuring absorbance $(260-280 \mathrm{~nm})$, its concentration was calculated to be $10 \mathrm{mg} / \mu \mathrm{L}$ for ORI Zymo and 23 $\mathrm{mg} / \mu \mathrm{L}$ for ORI.

Electroporation:The Z. mobilis cells were transformed by electroporation using BioRad GenePulser Xcell тM equipment. The colonies were transferred to an electroporation cuvette $(0.2 \mathrm{~cm})$, maintained at a low temperature and then processed as follows: $1.5 \mathrm{kV} / \mathrm{cm}^{3}, 75 \mathrm{kV} / \mathrm{cm}, 25 \mu \mathrm{F}$ and $200 \Omega$

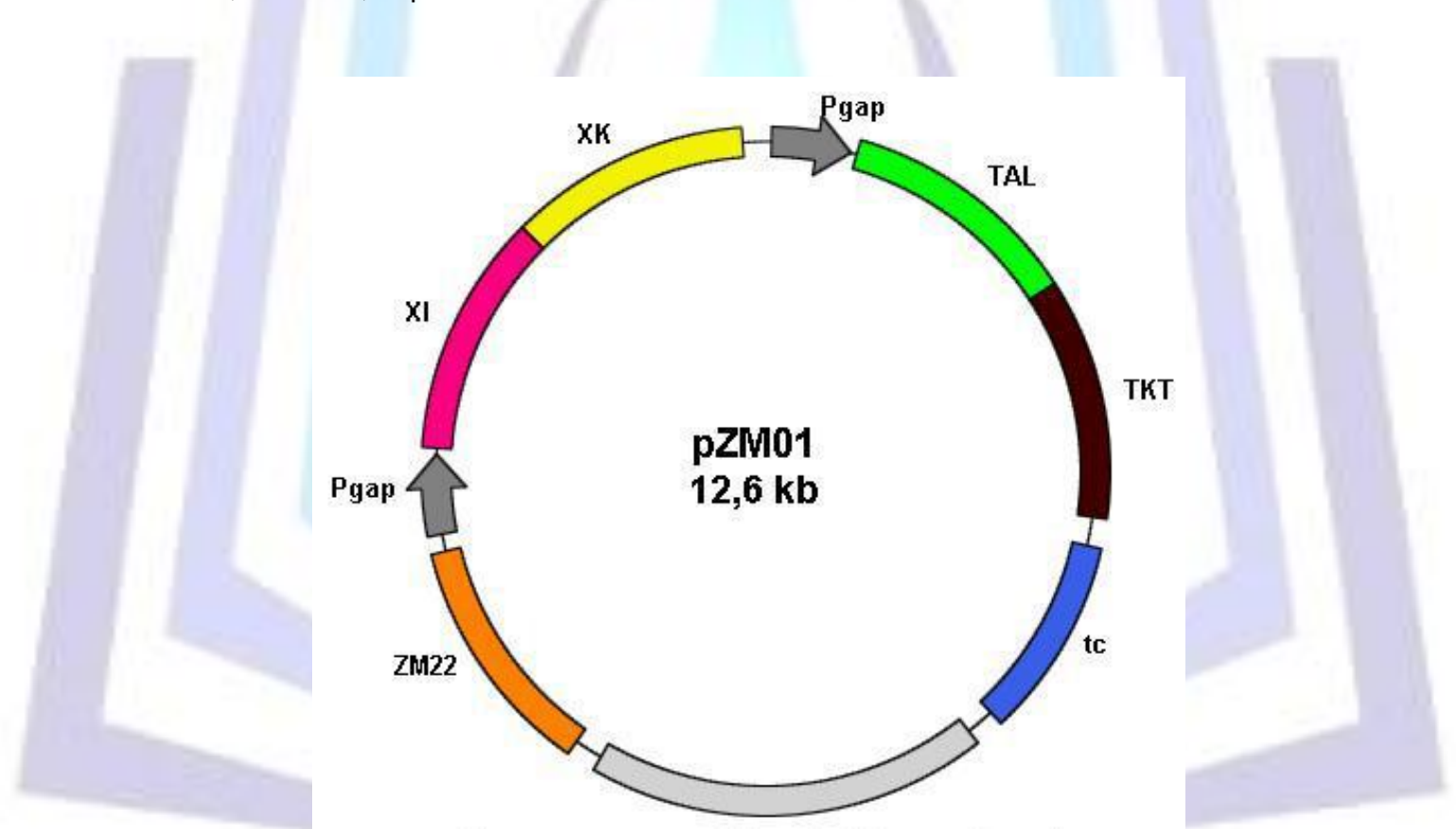

Fig 1: Map of the pZM01 plasmid, which has the double operon system for the genes of xylose metabolism.pGAP, glyceraldehyde-3-phosphate promoter; XI, xylose isomerase; XK, xylulokinase; TAL, transaldolase; TKT, transketolase; Tc, tetracycline resistance gene (4.2 kb); ZM22, origin of replication Z. mobilis (5.9 kb).

\section{Post-Processing}

Immediately after the bacterial cultures of Z. mobilis [ORI, ORI Zymo and the control without plasmid] were transformed by electroporation, they were incubated in RMG medium for $16 \mathrm{~h}$ as described by Picataggio et al. [27]. Subsequently, the three cultures were plated with RMG agar medium $(20 \mathrm{~g} / \mathrm{L})$ at $30^{\circ} \mathrm{C}$ for 7 days. Thus, transformed clones resistant to the antibiotic were grown in RM medium, and xylose and glucose were added at different concentrations to assess and enhance bacterial growth. Subsequently, isolated colonies that produced more biomass and rapid growth in these substrates were tested in terms of ethanol production.

Growth medium: The synthetic RM medium (rich medium) was used in the fermentation trials with a recombinant strain, as described by Mohagheghi et al. [28], Zhang [29] and Jeon et al. [30]. Glucose, xylose, and a combination of the two sugars were used as the RMG, RMX and RMGX mediums, 
respectively, for a carbon source at $20 \mathrm{~g} / \mathrm{L}$ concentrations for each sugar.

\section{RESULTS AND DISCUSSION}

After genetic modification of $Z$. mobilis, its cells were grown on glucose ( $20 \mathrm{~g} / \mathrm{L})$ and RM medium and $10 \mathrm{mg} / \mathrm{L}$ tetracycline were added, as shown in Figure 2.The naturally occurring strain did not grow, unlike the genetically modified strains ORI and ORI Zymo, which displayed several colonies, confirming that the genes exhibited tetracycline resistance. Because the antibiotic resistance gene is associated with the gene for xylose metabolism, the ORI Zymo strain apparently also changed simultaneously, as noted in the subsequent experiments.

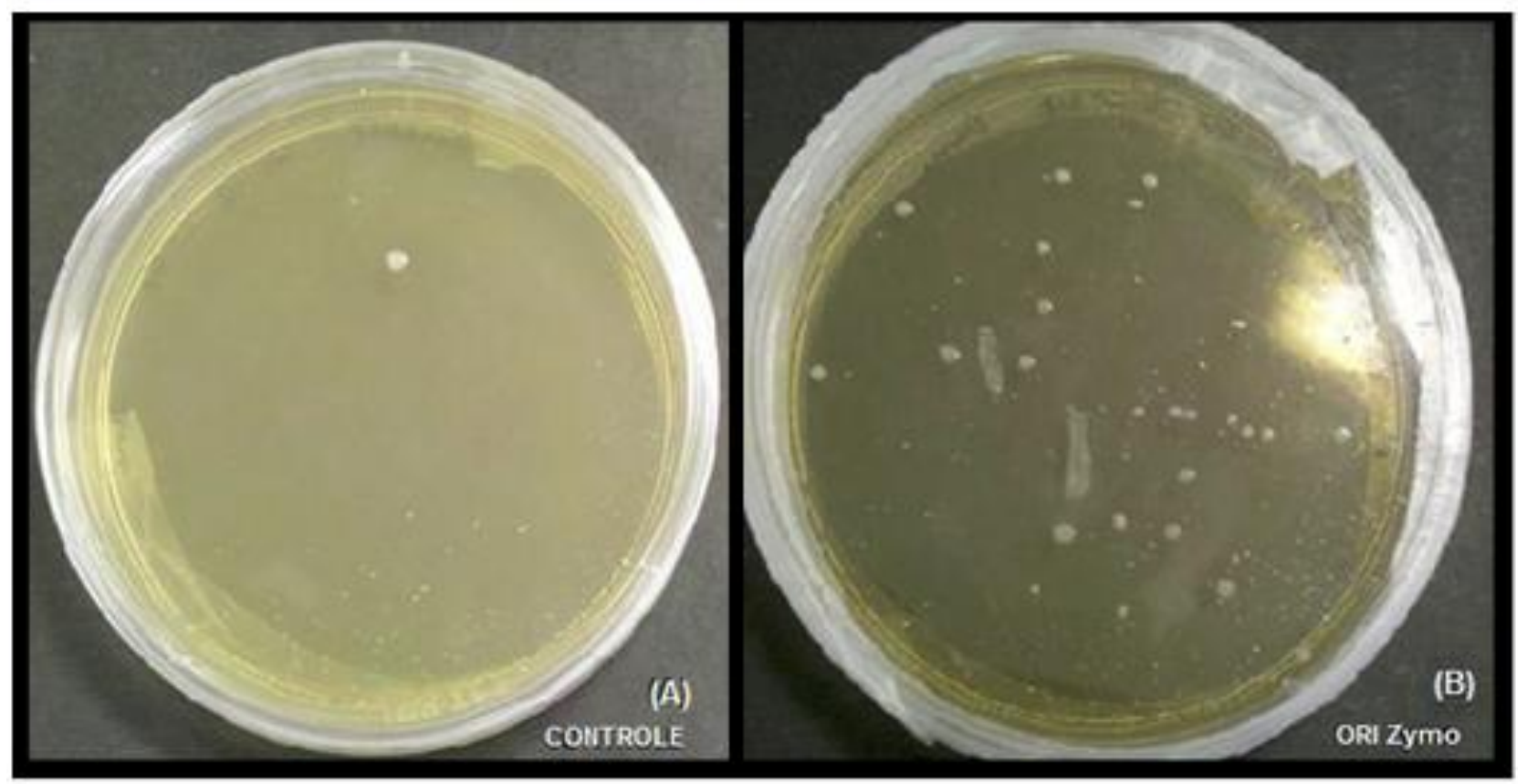

Fig 2: Growth of different strains of $Z$. mobilis after $168 \mathrm{~h}$ compared to the RMG medium containing glucose $(20 \mathrm{~g} / \mathrm{L}), \mathrm{KH}_{2} \mathrm{PO}_{4}(2 \mathrm{~g} / \mathrm{L})$, yeast extract $(10 \mathrm{~g} / \mathrm{L})$, agar $(20 \mathrm{~g} / \mathrm{L})$ and tetracycline $(10 \mathrm{mg} / \mathrm{L})$ at a temperature of $30^{\circ} \mathrm{C}$. (A) naturally occurring Z. mobilis; (B) ORI Zymo: bacterial plasmid that contains the antibiotic resistance gene and the gene for xylose metabolism.

\section{Metabolic adaptation in synthetic medium}

Several authors observed that the Zymomonas cells had difficulty converting xylose into ethanol after genetic transformation. The low ethanol yield from glucose and xylose mixtures can be ascribed to the preferential glucose uptake, generating high ethanol and acetic acid concentrations, which in turn hinder further xylose metabolism and reduce the rate of utilization of this pentose (Leksawasdi et al., 2001). Furthermore, the exogenous acetate stress or non-native xylose utilization shiftsthe redox balance, which leads to toxic intermediate xylitol formation and glycolysis inhibition [31]. Additionally, the competition for the only sugar transporter causes a reduction in the xylose metabolism compared to glucose [32]. Thus, some authors, e.g., Zhang et al. [33] and Viitanem et al. [34], have successfully developed the methodology of metabolic adaptation to circumvent this problem. Yanase et al. [35] reported the need for successive adaptation in recombinant species of Zymobacter palmae to increase ethanol yields.

Agrawall et al. [36] also reported that metabolic adaptation was essential for ethanol production by modified strains of $Z$. mobilis ZM4 (pZB5). Additionally, this strain has been identified as one of the best strains for xylose metabolism and has a high tolerance to ethanol, acetic acid and furfural. Zhang [29] found that the CP4 strain, which produced $24 \mathrm{~g} / \mathrm{L}$ ethanol from $15 \mathrm{~g} / \mathrm{L}$ glucose plus $35 \mathrm{~g} / \mathrm{L}$ xylose, was not as effective as the $8 \mathrm{~b}$ strain [6], which yielded $40 \mathrm{~g} / \mathrm{L}$ ethanol from the hydrolysate of paper waste. With the strain bearing the pZB5 plasmid, an ethanol production rate of $90 \mathrm{~g} / \mathrm{L}$ was achieved by applying the methodology of metabolic adaptation for 80 days with 30 adaptation cycles. The first colonies were grown in RMGX medium, and subsequently, the authors gradually increasedthe xylose concentration. Later, the selected strain had higher enzyme activity values for xylose isomerase and provided a higher conversion rate to ethanol and lower production of xylitol from this pentose. Nonetheless, the XI activity was still low compared to the other three enzymes, XK, TAL, and TKL. Additionally, the adapted and original colonies were sequenced, but no genetic difference could be identified. The authors reported a possible mutation involving transcription XI for both cultures, i.e., before and after metabolic adaptation.

Thus, the first adaptation cycles performed in the present study contained high glucose and low xylose concentrations. As the cycles advanced, the glucose concentration decreased, and the xylose concentration increased (Table 1). As noted 
above, immediately after genetic transformation, the microorganism showed slow growth, circa $170 \mathrm{~h}$, compared with the results developed by the native strain, which fermented glucose within $48 \mathrm{~h}$. The bacterial growth time after the $20^{\text {th }}$ cycle was reduced to approximately $72 \mathrm{~h}$, and the xylose uptake and the cell growth were increased.

The cell growth after the $26^{\text {th }}$ cycle reached $0.166 \mathrm{~g} / \mathrm{L}$ in approximately $70 \mathrm{~h}$, with xylose and glucose concentrations of 15 and $5 \mathrm{~g} / \mathrm{L}$, respectively. Cultures for the first adaptation cycles reached values of $0.05 \mathrm{~g} / \mathrm{L}$ in $96 \mathrm{~h}$ with medium containing $15 \mathrm{~g} / \mathrm{L}$ glucose and $5 \mathrm{~g} / \mathrm{L}$ xylose, which is more favorable for bacterial growth (more glucose). Therefore, although improvements regarding fermentation with this genetically modified $Z$. mobilis are still needed, the fermentation time and the ability to ferment xylose were both improved.

Table 1. Metabolic adaptation process during 50 cycles with varying glucose and xylose concentrations in RM medium.

\begin{tabular}{|c|c|c|c|c|c|}
\hline Cycles & Time(Days) & Initial Glucose (g/L) & Initial Xylose (g/L) & Biomass $^{\star}(\mathbf{g} / \mathbf{L})$ & Ethanol $^{\star}(\mathbf{g} / \mathbf{L})$ \\
\hline $1-10$ & 70 & 15 & 5 & 0.05 & 2.3 \\
\hline $11-19$ & 30 & 10 & 10 & 0.08 & 4.1 \\
\hline $20-25$ & 20 & 7.5 & 13.5 & 0.100 & 3.9 \\
\hline $26-30$ & 15 & 5 & 17.5 & 0.159 & 4.6 \\
\hline $31-40$ & 15 & 2.5 & 18.5 & 0.158 & 4.1 \\
\hline $41-50$ & 10 & 1.5 & & 156 & 4.2 \\
\hline
\end{tabular}

* Values correspond the results at the end of the last cycles.

Figure 3 summarizes the metabolic adaptation process insynthetic medium, suggesting that the recombinant $Z$. mobilis colonies increased ethanol production in the earlier cycles (1-30)but maintained such levels in subsequent cycles (31-50). This strategy allowed the recombinant to produce ethanol from xylose more efficiently becausehigher participation in ethanol production is derived from this pentose in the latter cycles.

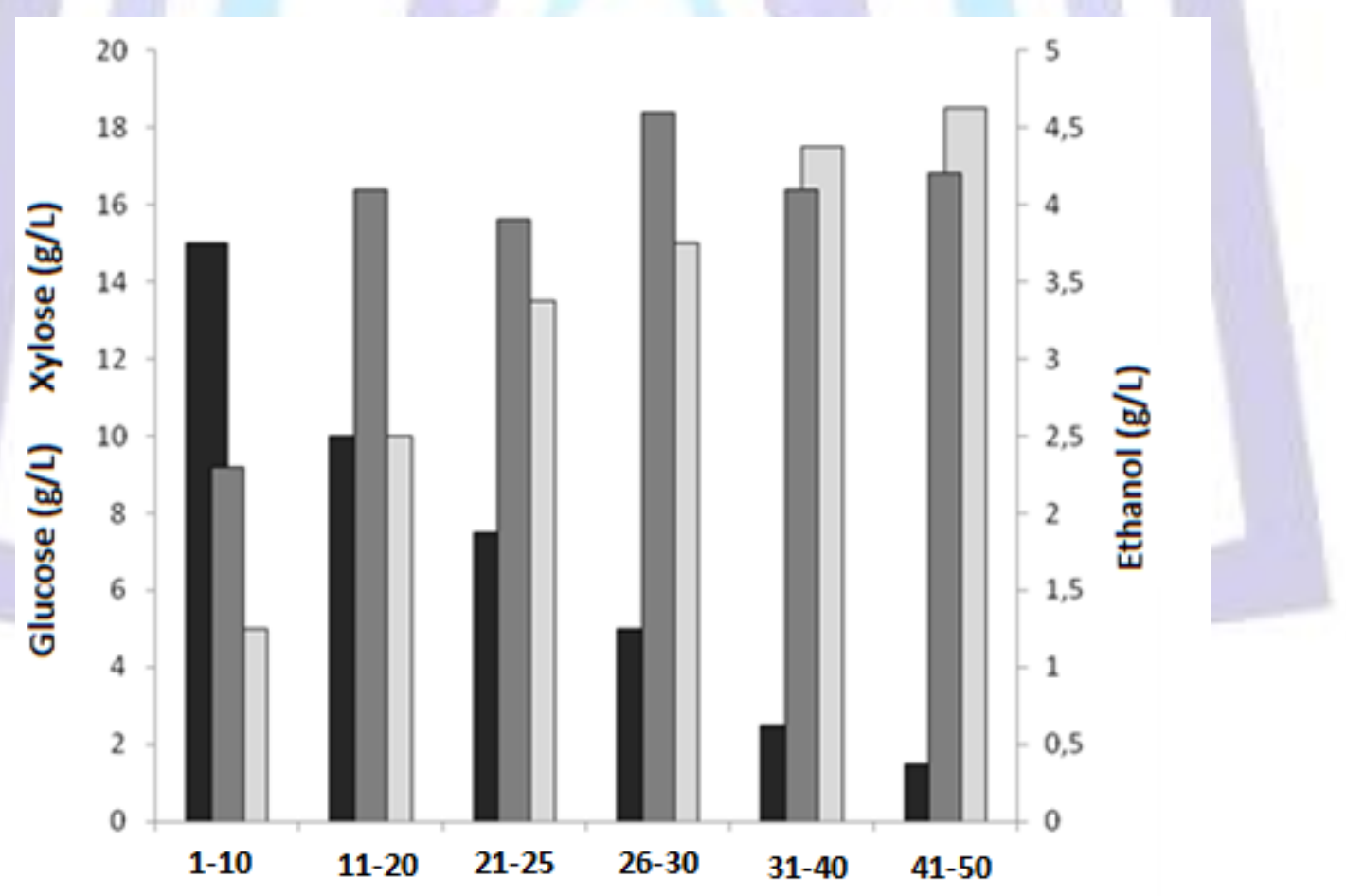

Adaptative cycles

Glucose $(\mathrm{g} / \mathrm{L}) \quad \square$ Xylose $(\mathrm{g} / \mathrm{L}) \quad$ Ethanol $(\mathrm{g} / \mathrm{L})$

Fig 3: Metabolic adaptation of a recombinant strain of $Z$. mobilis during 50 cycles to increase ethanol production from xylose.

Evaluation of ethanol production from SSCF through sequential experimental design 
Two Sequential $2^{2}$ Response Design Surfaces were developed to evaluatethe solid concentration of pretreated sugarcane bagasse and the proportion of hemicellulose hydrolysates in the SSCF process. The highest ethanol production was 25.0 $\mathrm{g} / \mathrm{L}$, which was achieved with a pretreated sugarcane bagasse concentration of 2.21:10 g:mL and proportion of hemicellulose hydrolysates of $20 \% \mathrm{v} / \mathrm{vin}$ the first Experimental Design. The second highest ethanol final concentration (10 $\mathrm{g} / \mathrm{L}$ ) was obtained in experiment 6 (Table 2), with a volumetric proportion of $45 \%$ of hemicellulose hydrolysate. Additionally, for the other experiments using $\mathrm{HH}=45 \%$, the ethanol production was low, indicating cell inhibition by toxic compounds generated during pretreatment (HMF, furfural and acetic acid), as widely reported by Padilla et al.

Subsequently, another Sequential $2^{2}$ Response Design Surface was developed to assess the same independent variables, although with higher levels of the S:L variable and lower levels of the HH variable. Table 3 shows that the highest ethanol concentration $(27.3 \mathrm{~g} / \mathrm{L})$ was obtained under the following conditions: $3: 10$ pre-treated sugarcane bagasse and $20 \% \mathrm{v} / \mathrm{v}$ hemicellulose hydrolysate. When the solid content was low, the ethanol concentration was severely reduced for any acid hydrolysate percentage (experiments 2, 4 and 10).

Table 2. First Sequential $2^{2}$ Response Design Surface for the evaluation of the percentage of hemicellulose hydrolysate $(\%)$ and the solid:liquid ratio $(\mathrm{g}: \mathrm{mL})$ of the pretreated sugarcane bagasse using the SSCF process for ethanol production by the recombinant strain $Z$. mobilis $C P 4$, adapted after the $25^{\text {th }}$ cycle in synthetic medium.

\begin{tabular}{|c|c|c|c|c|c|}
\hline \multirow{2}{*}{ Exp. } & \multicolumn{2}{|c|}{ Independent Variables } & \multicolumn{2}{c|}{ Conditions } & Response \\
\cline { 2 - 6 } & $\mathbf{H H}(\%)$ & S:L (g:mL) & Initial Glucose(g/L) & Initial Xylose (g/L) & Ethanol (g/L) \\
\hline 1 & 45.00 & $2.2: 10$ & 67.3 & 24.5 & $\mathbf{9 . 6}$ \\
\hline 2 & $\mathbf{2 0 . 0 0}$ & $\mathbf{2 . 0 : 1 0}$ & $\mathbf{5 7 . 4}$ & 61.1 & $\mathbf{2 5 . 0}$ \\
\hline 3 & 80.36 & $1.5: 10$ & 38.9 & 53.6 & 0.0 \\
\hline 4 & 70.00 & $2.0: 10$ & 61.4 & 27.9 & 7.4 \\
\hline 5 & 9.64 & $1.5: 10$ & 36.5 & 30.1 & 11.0 \\
\hline 6 & 45.00 & $1.5: 10$ & 33.8 & 32.0 & 2.2 \\
\hline 7 & 45.00 & $1.5: 10$ & 39.2 & 51.7 & 2.2 \\
\hline 8 & 45.00 & $1.5: 10$ & 36.1 & 33.3 & 1.5 \\
\hline 9 & 70.00 & $1.0: 10$ & 25.0 & 10.1 & 4.3 \\
\hline 10 & 45.00 & $1.5: 10$ & 34.6 & 40.5 & 7.6 \\
\hline 11 & 20.00 & $1.0: 10$ & 23.3 & 35.0 & 3.3 \\
\hline 12 & 45.00 & $0.8: 10$ & 14.9 & 37.5 & 4.0 \\
\hline 13 & 45.00 & $1.5: 10$ & & & \\
\hline
\end{tabular}

H. $\mathrm{H}=$ hemicellulosic hydrolyzed; $\mathrm{S}: \mathrm{L}=$ solid:liquid ratio.

Table 3. Second $2^{2}$ Response Surface Design for the evaluation of the percentage of hemicellulose hydrolysate (\%) and the solid: liquid ratio $(\mathrm{g}: \mathrm{mL})$ of the pretreated sugarcane bagasse using the SSCF process for ethanol production by recombinant $Z$. mobilis CP4 after the $25^{\text {th }}$ cycle in a synthetic medium.

\begin{tabular}{|c|c|c|c|c|c|}
\hline \multirow{2}{*}{ Ex. } & \multicolumn{2}{|c|}{ Independent Variables } & \multicolumn{2}{|c|}{ Conditions } & Response \\
\cline { 2 - 6 } & $\mathbf{H H}(\%)$ & $\mathbf{S : L}(\mathbf{g}: \mathbf{m L})$ & Initial Glucose(g/L) & Initial Xylose (g/L) & Ethanol (g/L) \\
\hline 1 & 20.50 & $2.0: 10$ & 59.3 & 12.5 & 18.2 \\
\hline 2 & 6.50 & $1.3: 10$ & 34.0 & 5.1 & $\mathbf{2 7 . 3}$ \\
\hline 3 & $\mathbf{2 0 . 5 0}$ & $\mathbf{3 . 0 : 1 0}$ & $\mathbf{4 8 . 9}$ & 18.7 & 5.1 \\
\hline 4 & 34.50 & $1.3: 10$ & 36.1 & 14.2 & 15.2 \\
\hline 5 & 20.50 & $2.0: 10$ & 57.8 & 0.6 & 24.0 \\
\hline 6 & 0.70 & $2.0: 10$ & 62.6 & 23.4 & 5.70 \\
\hline 7 & 40.30 & $2.0: 10$ & 65.2 & 8.0 & 15.6 \\
\hline 8 & 20.50 & $2.0: 10$ & 63.7 & 3.9 & 7.7 \\
\hline 9 & 6.50 & $2.7: 10$ & 51.3 & 23.5 & 4.5 \\
\hline 10 & 20.50 & $1.0: 10$ & & & 23.3 \\
\hline
\end{tabular}




\begin{tabular}{|c|c|c|c|c|c|}
\hline 11 & 34.50 & $2.7: 10$ & 73.0 & 21.3 & 5.2 \\
\hline 12 & 20.50 & $2.0: 10$ & 62.1 & 8.2 & 17.0 \\
\hline 13 & 20.50 & $2.0: 10$ & 60.4 & 12.6 & 8.8 \\
\hline
\end{tabular}

$\mathrm{HH}=$ hemicellulosic hydrolyzed; $\mathrm{S}: \mathrm{L}=$ solid:liquid ratio.

According to the variance analysis of SSFC Experimental Design 1 and SSCF Experimental Design 2, the linear model (2FI: two-factor interactions) and quadratic model adequately fit the experimental results, with correlation coefficients of 0.7 and 0.8 , insignificant pure error and insignificant lack of fit for the $90 \%$ confidence interval, as shown in Tables 4 and 5 , respectively. Furthermore, the two variance analyses show that the models are significant. For the first design, parameter A (hemicellulosic hydrolyzate) mainly influenced the final ethanol concentration, followed by the $A B$ interaction and parameter B (solid:liquid ratio). According to the model referring to SSCF Experiment 2, parameter B (solid:liquid ratio) was the most influential parameter, followed by $A$ (hemicellulosic hydrolyzate). The combinations that showed the strongest influence on the model were between $A B$, followed by $A^{2}$ and $B^{2}$.

Table 4. Variance analysis of the ethanol concentration reached in the first Experimental Planning SSCF1 process from sugarcane bagasse by recombinant $Z$. mobilis.

\begin{tabular}{|c|c|c|c|c|c|}
\hline & SS & DF & MS & F-Value & $p$-value \\
\hline Model & 366.91 & 3 & 122.30 & 6.76 & 0.0111 \\
\hline A & 217.04 & 1 & 217.04 & 12.00 & 0.0071 \\
\hline B & 60.22 & 1 & 60.22 & 3.33 & 0.1013 \\
\hline AB & 89.66 & 1 & 89.66 & 4.96 & 0.0530 \\
\hline Residue & 162.73 & 9 & 18.08 & & 0.3204 \\
\hline Lack of Fit & 109.96 & 5 & 21.99 & 1.67 & \\
\hline Pure Error & 52.77 & 4 & 13.19 & & \\
\hline Total Cor. & 529.64 & 12 & & & \\
\hline
\end{tabular}

Table 5. Variance analysis of the ethanol concentration reached in the second Experimental Planning SSCF2 process from sugarcane bagasse by recombinant $Z$. mobilis.

\begin{tabular}{|c|c|c|c|c|c|}
\hline & SS & DF & MS & F-Value & $p$-value \\
\hline Model & 700.29 & 5 & 140.06 & 5.71 & 0.0205 \\
\hline A & 201.31 & 1 & 201.31 & 8.20 & 0.0242 \\
\hline B & 360.93 & 1 & 360.93 & 14.71 & 0.0064 \\
\hline $\mathbf{A}^{2}$ & 114.43 & 1 & 114.43 & 4.66 & 0.0677 \\
\hline $\mathbf{B}^{2}$ & 18.21 & 1 & 18.21 & 0.74 & 0.4175 \\
\hline AB & 8.19 & 1 & 8.19 & 0.33 & 0.5817 \\
\hline Residue & 171.80 & 7 & 24.54 & & 0.1502 \\
\hline Lack of Fit & 120.36 & 3 & 40.12 & 3.12 & \\
\hline Pure Error & 51.43 & 4 & 12.86 & & \\
\hline Total Cor. & 872.08 & 12 & & & \\
\hline
\end{tabular}

$A=$ hemicellulosic hydrolyzed, $B=$ solid:liquid ratio; $S S=S$ Sum of squares; $D F=$ Degree of freedom; $M S=$ Mean square.

The model of SSCF1 and SSCF2 processes are represented by equations (2) and (3), respectively:

[Ethanol]: +5.84 - 5,21A + 2,74B - 4,73AB (2)

[Ethanol]: +14.96 - 5,06A 6,75B- 1,70A2 + - 1.17 B2 - 5.42 AB (3)

Figure 4 shows the contour surface, evaluating the hemicellulose hydrolysate percentage (\%), as well as the solid:liquid $(\mathrm{g}: \mathrm{mL})$ ratio of pretreated sugarcane bagasse through the SSCF1 process, in relation to ethanol production by the recombinant $Z$. mobilis CP4 strain. The surface indicates a reduction in parameter A (hemicellulose hydrolysate) and an increasein the concentration of parameter B (solid/liquid ratio). However, another design was necessary to optimize the experiments. 


\section{ISSN 2348-6201}

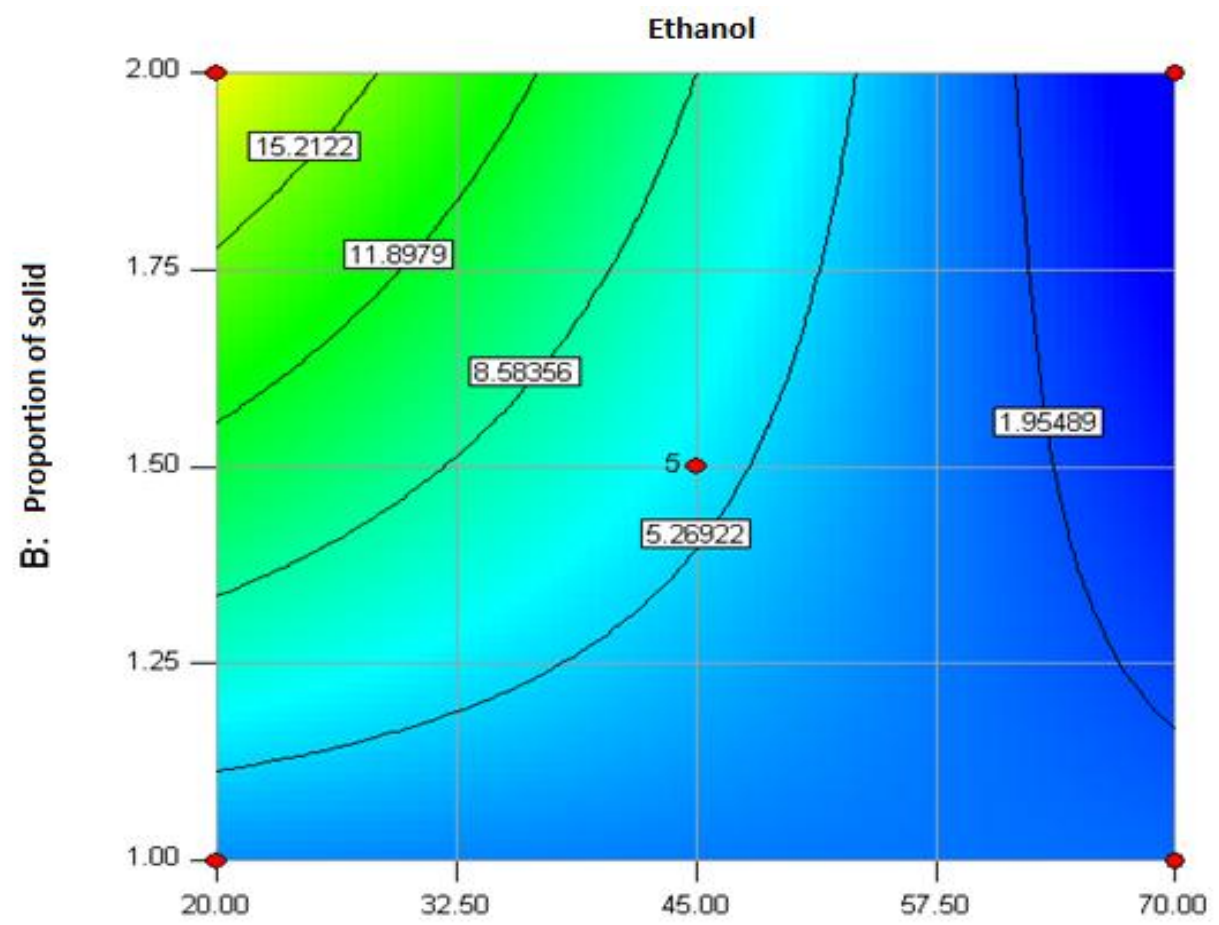

A: Hydrolyzate

Fig 4: Contour surface evaluating the combined effects of the parameters on the production of ethanol from the first Experimental Planning regarding the SSCF 1 process by the recombinant Z. mobilis strain.

Figure 5 shows the contour surface for the second Experimental Design, assessing the hemicellulose hydrolysate (\%) v/v and the solid:liquid ratio $(\mathrm{g}: \mathrm{mL})$; these were the same parameters used in the previous series of experiments, although with higher solid concentrations and lower volumetric proportions of acid hydrolysate.

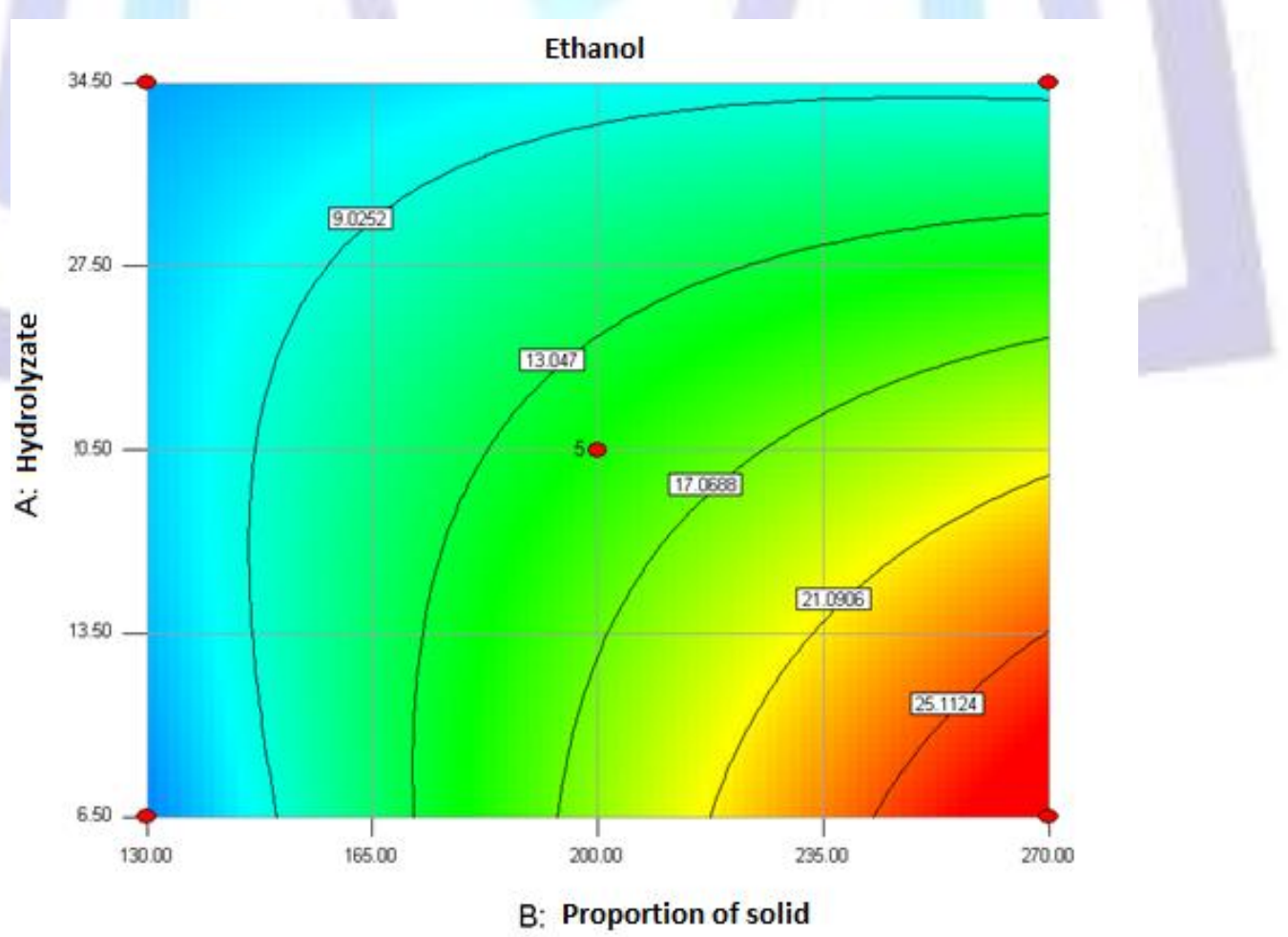

Fig 5: Contour surface evaluating the combined effects of the parameters on the production of ethanol in the second planning related by the SSCF 2 Process by the recombinant strain of Z. mobilis. 
According to the contour plot, the optimum region (in red) was reached through these experiments, and the highest ethanol production,approximately $25 \mathrm{~g} / \mathrm{L}$, was obtained, close to the maximum experimental value of $27 \mathrm{~g} / \mathrm{L}$, using the SSCF process, employing $30 \%$ of solids, $20.5 \%$ of hydrolyzed hemicellulosic, $10 \mathrm{mg} / \mathrm{L}$ of tetracycline, enzyme load of 25 FPU/g cellulignin, and $10 \%$ of the initial inoculum.

It was observerd that the recombinant bacterium Z. mobilis CP4 produces promising results as far as the metabolic adaptation cycles are performed. Some researchers also found it difficult in the pentose fermentation, generating residual concentrations xylose, as described by Davis et al. [17], reaching $11 \mathrm{~g} / \mathrm{L}$ of bioethanol and $12 \mathrm{~g} / \mathrm{L}$ of residual xylose concentration during 11 hours of process. Therefore, as indicated by several authors and proven in this study, the metabolic adaptation processes, as well as optimizations using the recombinant strain of $Z$. mobilis must be continuous with respect to maximizing the production of ethanol and microbial biomass.

\section{CONCLUSIONS}

Genetic and metabolic engineering still present the best and possibly only alternatives to making Z. mobilis capable of fermenting lignocellulosic hydrolysates on an industrial scale. However, the difficulties in metabolizing xylose by recombinant $Z$. mobilis strains might be related to the inefficient xylose transport, as this approach was not envisaged in the present work. The vector insert in the wild strain contained only the genes responsible for xylose metabolism and did not include the genes coding for xylose assimilation. The evidence that the recombinant strain consumed xylose was due to its transportation through hexose permeases [37]. Additionally, the relatively low ethanol concentration might be ascribed to the inhibition of microbial growth by toxic compounds generated in the hydrolysates, which arise from acid pretreatment. Brazilian studies using molecular biology techniques in this organism are very recent. The LADEBIO research center,a pioneer in this subject, employs such bacteria, transforming and developing the optimization of enzymatic hydrolysis and simultaneous co-fermentation (SSCF) from an abundant agroindustrial waste - sugarcane bagasse.

This study demonstrated a positive aspect of adopting the metabolic adaptation strategy. The recombinant strain exhibited increased ability to uptake and ferment xylose upon transfer into media containing an increased xylose concentration.

Efforts were made to optimize the simultaneous saccharification and co-fermentation of sugarcane bagasse cellulignin with different proportions of hemicellulosic acid hydrolysate. This investigation, carried out with two sequential experimental designs, resulted in ethanol concentrations varying from zero to $27.3 \mathrm{~g} / \mathrm{L}$. The optimum conditions for achieving the highest ethanol was a solid:liquid ratio of approximately $3: 10$ and a volumetric hemicellulose hydrolysate proportion of $20.5 \%$. These findings were statistically validated using the linear model (2FI: two-factor interactions) and the quadratic model adequately in the designs, which presented correlation coefficients of 0.7 and 0.8 , respectively insignificant pure error and insignificant lack of fit for the $90 \%$ confidence interval.

\section{ACKNOWLEDGMENTS}

Federal University of Rio de Janeiro, Laboratories of Bioprocess Development; CNPQ; PETROBRÁS.

\section{REFERENCES}

[1] CONAB, 2014. Companhia Nacional de Abastecimento: <http://www.conab.gov.br>.

[2] Betancur, G. J. V \& Pereira, Jr. N. 2010. Sugarcane bagasse as feedstock for second generation ethanol production. Part I: diluted acid pre-treatment optimization. Electronic Journal of Biotechnology. 13: 5 (June 2010).

[3] Barcelos, C. A.; Maeda, R. N.; Betancur, G. J. V.; Pereira, N. , 2012. The Essentialness of Delignification on Enzymatic Hydrolysis of Sugar Cane Bagasse Cellulignin for Second Generation Ethanol Production. Waste and Biomass Valorization, 3, 255-260.

[4] Liegh, D.; Scopes, R. K.; Rogers, P. L. 1985. A proposed pathway for sorbitol production by Zymomonas mobilis. Appl. Microbiol. Biotechnol. 20, 413-415.

[5] Kannan, T. R.; Sangiliyandi, G.; Gunasekaran, P. 1998. Improved ethanol production from sucrose by a mutant of Zymomonas mobilis lacking sucrases in immobilized cell fermentation. Enzyme and Microbial Technology, 22, 179184.

[6] Zhang, J.; Lynd, L. R. 2010. Ethanol production from paper sludge by simultaneous saccharification and cofermentation using recombinant xylose-fermenting microorganisms. Biotechnology and Bioengineering, 107: 2.

[7] Yanase, H.; Nozaki, K.; Okamoto, K. Ethanol production from cellulosic materials by genetically engineered Zymomonas mobilis. 2005. Biotechnology Letters, 27, 259-263.

[8] He, M. et al.,Zymomonas mobilis: a novel platform for future biorefineries. 2014. Biotechnology for Biofuels, 7:101 doi:10.1186/1754-6834-7-101.

[9] Liu, C-Q.; Goodman, A.E.; Dunn, N.W.1988. Expression of Cloned Xanthomonas D-Xylose Catabolic Genes in Zymomonas mobilis. Journal of Biotechnology, 7, 61-70.

[10] Feldmann, S. D.; Sahm, H.; Sprenger, G. A. 1992. Pentose metabolism in Zymomonas mobilis wild-type and recombinant strains. Applied Microbiology and Biotechnology, 38: 3, 354-361. 
[11] Matsushikaa, A.; Goshimaa, T.; Fujii, T.; Inouea, H.; Sawayamab, S.; Yanoa, S. 2012. Characterization of nonoxidative transaldolase and transketolase enzymes in the pentose phosphate pathway with regard to xylose utilization by recombinant Saccharomyces cerevisiae. Enzyme and Microbial Technology, 51, 16- 25.

[12] Yanase, H.; Sato, D.; Yamamoto, K.; Matsuda, S.; Yamamoto, S.; Okamoto, K. 2007. Genetic Engineering of Zymobacter palmae for Production of Ethanol from Xylose. Applied and Environmental Microbiology, 2592-2599.

[13] Mohagheghi, A.; Ruth, M.; Schell, D. 2006. Conditioning hemicellulose hydrolysates for fermentation Effects of overliming $\mathrm{pH}$ on sucrose and ethanol yields. Process Biochemistry, 41, 1806-1811.

[14] Zhang, M.; Eddy, C.; Deanda, K.; Finkestein, M.; Picataggio, S. 1995. Metabolic engineering of a pentose metabolism pathway in ethanologenic Zymomonas mobilis. Science, 267: 5195, 240-243.

[15] Mohagheghi, A.; Dowe, N.; SchelL, D.; Chou, Y-C.; Eddy, C.; Zhang, M. 2004. Performance of a newly developed integrant of Zymomonas mobilis for ethanol production on corn stover hydrolysate. Biotechnology Letters, 26: 4, 321325.

[16] Zhang, J.; Lynd, L. R. 2010. Ethanol production from paper sludge by simultaneous saccharification and cofermentation using recombinant xylose-fermenting microorganisms. Biotechnology and Bioengineering, 107: 2.

[17] Davis, L.; Jeon, Y.; Svenson, C.; Rogers, P.; Pearce, J.; Peirisa, P. 2005. Evaluation of wheat stillage for ethanol production by recombinant Zymomonas mobilis. Biomass and Bioenergy, 29, 49-59.

[18] Zhang, X. et al., 2013. Use of a Tn5-based transposon system to create a cost-effective Zymomonas mobilis for ethanol production from lignocelluloses. Microbial Cell Factories, 12:41, doi:10.1186/1475-2859-12-41.

[19] Caimi, P. G.; Mccole, L.; Tao, L.; Tombj-F.; Viitanen, P. V. 2012. Xylose utilization in recombinant Zymomonas- Us patent 20120156746.

[20] Aristidou, A.; Penttilä, M. 2000. Metabolic engineering applications to renewable resource utilization.Current Opinion in Biotechnology, 11, 187-198.

[21] Vasques, M. P. 2007 Produção de Etanol a partir de Bagaço de Cana-de-Açúcar. Doctoral thesis, Federal University of Rio de Janeiro.

[22] Ghose, T. K. 1987. Measurement of cellulase activities. Pure \& Applied Chemistry, 59, 257-268

[23] Box, G. E. P., Hunter, W. G., \& Hunter, J. S. 1978. Statistics for experimenters. New York: Wiley.

[24] Arvanitis, N.; Pappas, K. M.; Kolios, G.; Afendra, A. S.; Typas, M. A.; Drainas, C. 2000. Characterization and Replication Properties of the Zymomonas mobilis ATCC 10988 Plasmids pZMO1 and pZMO2. Plasmid, 44, 127137.

[25] Azevedo, M. O.; Felipe, M. S. S.; Brigido, M. M.; Maranhão, A. Q.; Souza, M. T. 2003. Técnicas básicas em biologia molecular. Editora Universidade de Brasília.

[26] Liang, C-C.; Lee, W-C. 1998. Characteristics and transformation of Zymomonas mobilis with plasmid Pkt230 by electroporation. Bioprocess Engineering, 19, 81-85.

[27] Picataggio, S. K., Zhang, M., Eddy, C. K., Deanda, K. A., And Finkelstein, M. 1996. Recombinant Zymomonas for Xylose Fermentation.US patent 5,514,583.

[28] Mohagheghi, A.; Evans, K.; Chou, Y. C.; Zhang, M. 2002. Cofermentation of glucose, xylose, and arabinose by genomic DNA-integrated xylose/arabinose fermenting strain of Zymomonas mobilis AX101. Applied Biochemical and Biotechnology, 98: 100, 885-898.

[29] Zhang, M. 2003. Recombinant Zymomonas mobilis with improved xylose fermentation- US Patent 6566107.

[30] Jeon, Y. J.; Svenson, C. J.; Rogers, P. L. 2005. Over-expression of xylulokinase in a xylose-metabolising recombinant strain of Zymomonas mobilis. FEMS Microbiology Letters, 244, 85-92.

[31] Yang, S. et al., 2014. Insights into acetate toxicity in Zymomonas mobilis 8b using different substrates. Biotechnology for Biofuels, 7:140 doi:10.1186/s13068-014-0140-8.

[32] Kim, J-H.; Block, D. E.; Mills, D. 2010. A. Simultaneous consumption of pentose and hexose sugars: an optimal microbial phenotype for efficient fermentation of lignocellulosic biomass. Applied Microbiology and Biotechnology, 88: 5, 1077-1085.

[33] Zhang, M.; Chou, Y.; Howe, W.; Eddy, C.; Evans, K.; Mohagheghi, A. 2002. Zymomonas pentose-sugar fermenting strains and uses there of. US 2003/0162271 A1.

[34] Viitanen, P.; Mccutchen, C.; Chou, Y.; Zhang, M. 2008. Xylitol synthesis mutant of xylose-utilizing Zymomonas for ethanol production. WO Patent, WO/2008/133,638.

[35] Yanase, H.; Sato, D.; Yamamoto, K.; Matsuda, S.; Yamamoto, S.; Okamoto, K. 2007. Genetic Engineering of Zymobacter palmae for Production of Ethanol from Xylose. Applied and Environmental Microbiology, 2592-2599. 
[36] Agrawal, M.; Mao, Z.; Chen, R. R. 2011. Adaptation Yields a Highly Efficient Xylose-Fermenting Zymomonas mobilis Strain. Biotechnology and Bioengineering, 108: 4.

[37] Vilela et al., 2015. Enhanced xylose fermentation and ethanol production by engineered Saccharomyces cerevisiae strain. AMB Express, 5: 16.

\section{Author' biography with Photo}

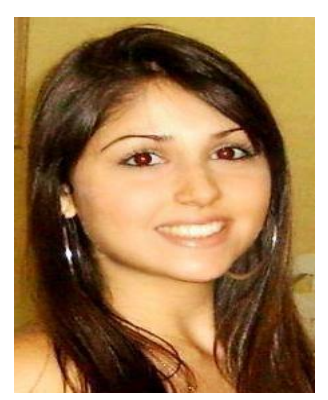

Danielle da Silveira dos Santos Martins is PhD in Sciences from the Pos Graduation Program on Tecnology in Biochemical and Chemical Process from School of Chemistry/ Federal University of Rio de Janeiro, Brazil. The postdoctoral researcher acts specifically in biotechnology with emphasis on Industrial Microbiology and Fermentation; participates of theoretical- experimental projects development, scientific research and development in bioprocesses, student's guides, reports development, as lectures and conferences. Are subjects of research, the process development aimed at biofuels production, enzymes, biosurfactants, organic acids, waste treatment and industrial effluents, as molecular biology techniques development. 